九州大学学術情報リポジトリ

Kyushu University Institutional Repository

\title{
Analysis of Thermal Performance of Mica-Mineral Reinforced Intumescent Coating for Structural Steel Application
}

\section{Yasmin Mohd-Azmi}

Department of Mechanical Engineering, Universiti Teknologi PETRONAS

\section{Ahmad, Faiz}

Department of Mechanical Engineering, Universiti Teknologi PETRONAS

Kabir, Sarower

Department of Mechanical Engineering, Universiti Teknologi PETRONAS

Nosbi, Norlin

Department of Mechanical Engineering, Universiti Teknologi PETRONAS

他

https://doi.org/10.5109/4491648

出版情報 : Evergreen. 8 (3)，pp.565-573，2021-09. 九州大学グリーンテクノロジー研究教育センター バージョン：

権利関係 : 


\title{
Analysis of Thermal Performance of Mica-Mineral Reinforced Intumescent Coating for Structural Steel Application
}

\author{
Yasmin Mohd-Azmi ${ }^{1}$, Faiz Ahmad ${ }^{1 *}$, Sarower Kabir ${ }^{1}$, Norlin Nosbi ${ }^{1}$, \\ Yeoh Guan Heng ${ }^{2}$, Ayesha Zulfiqar ${ }^{3}$ \\ ${ }^{1}$ Department of Mechanical Engineering, Universiti Teknologi PETRONAS, Malaysia \\ ${ }^{2}$ School of Mechanical \& Manufacturing Engineering, University of New South Wales, Australia \\ ${ }^{3}$ Institute of Chemical Engineering and Technology, University of Punjab, Pakistan \\ E-mail: faizahmad@utp.edu.my
}

(Received February 11, 2021; Revised August 23, 2021; accepted August 30, 2021).

\begin{abstract}
Intumescent coating reinforce mica was developed and studied in terms of their physical appearance, thermal properties, composition, and morphology. 6 samples, including control formulation, were developed by varying percentage of mica to binder from 0 to $5 \%$. Control fire test shows an increase of expansion when the percentage of mica increases but decreases when more than $4 \%$ of mica was used. The thermal stability of the samples with $3 \%$ mica was improved with a degradation rate of $0.047 \mathrm{wt} . \% /$ min compared to the control formulation $0.091 \mathrm{wt} \% / \mathrm{min}$ suggested coming from silicon phosphate oxide composition emerged on XRD analysis. Silicon phosphate oxide was known to enhance the antioxidation of the char and thermal stability of the char. A homogenous surface with a smaller pore was also observed on the char structure of MC3 coming from the ceramization process, which creates a ceramics layer on the surface, thus improve the insulation properties of the coating.
\end{abstract}

Keywords: Intumescent Coating, Mica, Zinc Borate, Structural Steel, Flame-Retardant, Passive Fire Protection

\section{Introduction}

Intumescent coating, commonly known as intumescent paint, is used as passive fire protection against significant types of fire - cellulosic and hydrocarbon, with the latter has more stringent rules applied in a building or any structural. The difference between any standard paint is that intumescent coating swell when exposed to fire, thus delaying the heat transfer to the protected substrate. The coating mechanism is that when it is exposed to heat, the coating will act as a thermal barrier by expanding. It increases in volume and decreases the density to form a char and protect the substrate from further heat transfer for 30 minutes to three hours, depending on the industry's requirement. For a cellulosic fire protection product, the fire integrity must be 30 minutes for $\mathrm{B}$ fire-rated product and 60 minutes for A fire-rated product ${ }^{1)}$. This condition will be applied to the sample exposed to an actual fire situation in this project. Typically, the primary ingredient of the intumescent compromises three materials - acid source, carbon source, and blowing agent ${ }^{2), 33}$. These three formulations are needed to be arranged for their chemical and physical properties in a way for them to become an effective barrier. When a fire breaks, the acid source will break down to produce a mineral acid. It will take part in the dehydration of the carbonisation agent to form a carbon char. The char was then swelled from the inert gas coming from the decomposition of the blowing agent. This expansion providing insulation of a multicellular protective layer that limits the heat transfer to the protected substrate ${ }^{4), 5}$.

The intumescent coating can be separated into three majors: waterborne, solvent-based, and solvent-free, with a thickness between $0.5-30 \mathrm{~mm}$ depending on application types of application ${ }^{6,7)}$. The coating applies typically using a brush, roller, or airless spray-on or off-site. Previously it was implemented more into construction, oil and gas, and automotive industries. However, with an increase of urban population which is predicted to exceed six billion ( $70 \%$ of the world's population) in the $2050 \mathrm{~s}^{8)}$, the concern of the safety in confine building and the highly advanced machine that cost millions, causing more industrial people and domestic adopting this type of coating on their building with the intention of not only saving people life but also reducing the damage of their asset in the case of fire. According to Cision PR Newswire, the global intumescent coating market anticipated reaching USD 1.31 billion by 2025 as the awareness on the importance of the coating in their building rises. This establishment is also anticipated to rise as the essential development driver over the following nine a long time ${ }^{9)}$. The first intumescent behaviour reported was in 1982 with references to flame retardancy of textiles, but the word of intumescent was not used in the text until 1970 where 
Vander published the first comprehensive paper. Thus, from that year, the coating improvised from the essential three ingredients to the introduction of addictive such as zinc borate, boric acid in 1980-1990. In recent years, the more advanced formulation was created with the emerged addition of filler concept in the coating, which includes inorganic and organic fillers to improve the performance of the coating ${ }^{10)}$.

Mica is a group of complex minerals with divergent chemical composition and physical properties found in rock-forming mineral - igneous, sedimentary, metamorphic. The group compromise of hydrous potassium silicate minerals ${ }^{11)}$ with a general formula of $\mathrm{XY} 2-3 \mathrm{Z} 4 \mathrm{O} 10(\mathrm{OH}, \mathrm{F}) 2$ where $\mathrm{X}=\mathrm{K}, \mathrm{Na}, \mathrm{Ba}, \mathrm{Ca}$, Cs, (H3O), (NH4); Y = Al, Mg, Fe2+, Li, Cr, Mn, V, Zn; and $\mathrm{Z}=\mathrm{Si}, \mathrm{Al}, \mathrm{Fe} 3+$, Ti. Silica was known to promote heat stabilization $^{12), 13)}$. Their perfect cleavage simply identified mica into thin slices, often having a hexagonal outline with a sheet structure whose basic units consist of two polymerised sheets of silica tetrahedrons (SiO4).

In industrial term, mica was commonly known as a clay mineral. It was used in different fields because of its low thermal and electrical conductivity, flexibility, elasticity, and infusibility properties. The application includes but not limited to the processing industrial from a beauty product, personal care, architecture, optical instrument, painting industry to industrial insulation material. It is also a popular material among the cosmetic industry for having properties that glow and radiance to their appearance ${ }^{14) .}$

A various study was done to evaluate the effect of mica as a filler such as mica filled polymer composite. One composite research was completed to evaluate polymethyl methacrylate reinforced with mica filler, thus showing a significant increase in elastic moduli with increasing mica concentration with optical microscopy analysis displaying good bonding between the material and successfully forming a cohesive composite ${ }^{15)}$. In the development of flame retardant on the polymeric material, clay minerals are fewer apart from montmorillonite. A raw mica powder of muscovite type was recorded having high thermal stability with loss of mass of $5 \%$ at around $700^{\circ} \mathrm{C}$ associated to dihydroxylation process ${ }^{16)}$, which are outstanding properties to be introduced in the intumescent coating. The closest study of mica material on intumescent flame-retardant coating was done by Zia et on synergetic of the material with wollastonite as a filler. The study found the interaction leads to boron phosphate, silicon phosphate oxide, and sassolite enhance the antioxidation and thermal stability of the char $^{17)}$.

The present study aimed to gauge the effects of micamineral on the performance of intumescent flameretardant coating by varying its weight percentage. In addition, heat-resistant test, char morphology, thermal performance analysis was carried out to evaluate mica mineral reinforced intumescent coating performance.

\section{Experimental \& Characterization}

In this research, six sets of intumescent coating samples varying the percentage of mica filler in the formulation and a control formulation were developed. The samples were prepared for further testing and analysis.

\subsection{Materials}

DGEBA with Equivalent Weight (E.E.W) 188, Expandable Graphite (EG), and Zinc Borate were purchased from Mc-Growth Chemical Sdn. Bhd. Boric Acid (BA), melamine (MEL) was obtained from SigmaAldrich (M) Sdn. Bhd. Malaysia. Clariant (Malaysia) Sdn. Bhd. supplied ammonium polyphosphate (APP).

\subsection{Preparation of Coating}

All the materials were weighed according to their respective weight percentage as per Table 1 . Boric acid, zinc borate, melamine, and ammonium polyphosphate were ground for one minute before mixed with expandable graphite and epoxy in a sheer mixer machine at $30 \mathrm{rpm}$ for 15 minutes. The hardener was slowly introduced into the mixer to help crosslink the materials. The epoxy used in this research is DGEBA $\left(\mathrm{C}_{21} \mathrm{H}_{24} \mathrm{O}_{4}\right)$ and TETA $\mathrm{C}_{6} \mathrm{H}_{18} \mathrm{~N}_{4}$ . The ratio of the epoxy: binder is $2: 1$. The process was continued for another 10 minutes. The coating is then applied to ASTM A36 steel substrate of a thickness of $1.5 \mathrm{~mm}$ using spatula before leaving to cure at room temperature. The thickness was measure using thickness gauge and vernier calliper. The thickness of the coating with the substrate was measured to calculate the Intumescent factor (IF).

Table 1: Intumescent Coating Composition

\begin{tabular}{|c|c|c|c|c|c|c|c|}
\hline \multirow{2}{*}{ Sl. } & \multicolumn{7}{|c|}{ Composition } \\
\cline { 2 - 8 } & $\begin{array}{c}\text { EG } \\
(\%)\end{array}$ & $\begin{array}{c}\text { BA } \\
\mathbf{( \% )}\end{array}$ & $\begin{array}{c}\text { ZB } \\
(\%)\end{array}$ & $\begin{array}{c}\text { APP } \\
(\%)\end{array}$ & $\begin{array}{c}\text { MEL } \\
(\%)\end{array}$ & $\begin{array}{c}\text { Bind. } \\
(\%)\end{array}$ & $\begin{array}{c}\text { Mica } \\
(\%)\end{array}$ \\
\hline MC0 & 5.5 & 6.11 & 5 & 11.23 & 5.5 & 66.66 & 0 \\
\hline MC1 & 5.5 & 6.11 & 5 & 11.23 & 5.5 & 65.66 & 1 \\
\hline MC2 & 5.5 & 6.11 & 5 & 11.23 & 5.5 & 64.66 & 2 \\
\hline MC3 & 5.5 & 6.11 & 5 & 11.23 & 5.5 & 63.66 & 3 \\
\hline MC4 & 5.5 & 6.11 & 5 & 11.23 & 5.5 & 62.66 & 4 \\
\hline MC5 & 5.5 & 6.11 & 5 & 11.23 & 5.5 & 61.66 & 5 \\
\hline
\end{tabular}

\section{Characterisation and Analysis}

\subsection{Direct Fire Test}

To evaluate the thermal performance of the coating, the cured samples were exposed to a lab-scale direct fire test as the setup as per Fig. 1 inside a heat-shielding box. The samples back substrate was attached with three thermocouples and hold with a retort stand. The coating sample was then exposed to butane gas fire, and the temperature of the back substrate and the physical observation was recorded for 1 hour. 


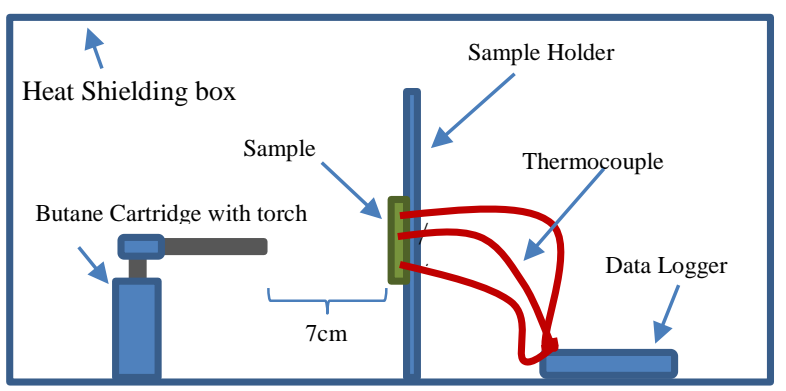

Fig. 1: Direct Fire test experimental setup inside a heatshielding box

\subsection{Control Fire Test (Carbolite Furnace)}

A control fire test was performed inside Carbolite Gero Furnace to examine the morphology and expansion of char in a controlled environment. The cured coating was burned for 1 hour at a temperature of $600^{\circ} \mathrm{C}$ with a $20^{\circ} \mathrm{C} / \mathrm{min}$ rate. The samples thickness before and after burning was recorded, and intumescent factor (IF) was calculated based on the following equation.

$$
\mathrm{IF}=\left(\mathrm{D}_{2}-\mathrm{D}_{0}\right) /\left(\mathrm{D}_{1}-\mathrm{D}_{0}\right)
$$

$D_{2}$ is the thickness of the char with the substrate, $D_{1}$ is the thickness of coating with the substrate, and $\mathrm{D}_{0}$ is the thickness of the steel substrate.

\subsection{Thermogravimetric Analysis (TGA)}

The analysis is essential to analyse the thermal performance of the intumescent coating, in which physical and chemical changes are measured as a function of time and temperature with a constant heating rate. Perkin Elmer Pyris Thermogravimetric Analyser was used for this analysis to determine the samples' residual mass and thermal behaviour using a heating rate of $10^{\circ} \mathrm{C} / \mathrm{min}$ under nitrogen flow from room temperature till $900^{\circ} \mathrm{C}$.

\subsection{Field Emission Scanning Electron Microscope (FESEM)}

Field Emission Scanning Electron Microscope (FESEM) is a microscope that uses electrons rather than light to form an image. FESEM can produce a very highresolution image of a sample surface, revealing details about 1 to $5 \mathrm{~nm}$ in size. For this study, Zeiss SUPRA 55VP FEG-SEM operated at $5 \mathrm{kV}$ was used to study the char's surface and cross-section morphology.

\subsection{X-ray Diffraction (XRD)}

$\mathrm{X}$-ray diffraction (XRD) is a method to determine the char composition and crystalline properties of materials. The analysis used to study the composition of residual char of intumescent coating produces at control fire temperature. XRD measurement was performed on a Bruker AXS D8 Advance Diffractometer using $\mathrm{Cu} \mathrm{K} \alpha$ radiation and nickel filter $(\mathrm{k}=0.150595 \mathrm{~nm})$ in the range of $10<2 \theta<90$. The sample for the analysis will be prepared by crushing the expanded char obtain from the Carbolite furnace test into a powder.

\section{Results \& Discussions}

\subsection{Fire Test}

The samples were developed in lab condition and dried at room temperature. All the samples have a smooth and glossy surface finish, as shown in the first column of Fig. 2. Coating's colour becomes less brown as the percentage of mica increases due to the pigmentation properties of mica. All the samples were subjected to a control fire test and direct fire test to evaluate their thermal performance. Char obtains after burning for control fire test are shown in second till the fourth column in Fig. 2 while char obtain from direct fire test presented in Fig. 4.

In a control fire environment, the thickness of the samples with the substrate was first measured. It was then exposed to $600{ }^{\circ} \mathrm{C}$ for 1 hour at a rate of $20{ }^{\circ} \mathrm{C} / \mathrm{min}$ to evaluate the char expansion and intumescent factor (IF). IF was one of the critical factors to evaluate the mechanical performance of the samples but not limited. Designing the formulation aims to gain a charred multicellular layer to reduce the heat transfer steel plate $^{18), 19)}$. The chart showing an increasing IF trend when the percentage of mica increases but dropping significantly when more than 5\% of mica was used in the formulation shown in sample MC5. Coating without mica giving the lowest IF value with a 6.25 ratio percentage. The IF values of the mica sample following the order with 7.357, 7.435, 8.603, 11.949 and 7.015 for MC1 until MC5. MC0, MC1 and MC5 samples showing a break in adhesive bonding between char and the steel substrate after a cross-section of samples was performed as presented with a red circle in Fig. 2 with part of MC5's char was detached even before a cross-section cut was performed. In contrast, a complete char appeared at the substrate's bottom for MC2, MC3 and MC4, indicating a successful char intact.

A $10 \mathrm{~cm} \times 10 \mathrm{~cm} \times 1.5 \mathrm{~cm}$ samples were also prepared following section 0 for direct fire test. The dried coating samples were exposed to fire for 1 hour, and the back temperature of the steel substrate was recorded with a data logger to evaluate the performance of coating against actual fire. The char and back temperature of the substrate after the test are presented in Fig. 4 and Fig. 6.

All mica samples start expanding well at an early stage of exposure to fire, but smoke appears as early as 5 minutes before quickly dissipate. MC2, MC5 takes longer times for fire spreading throughout the coating to be extinguished compare to MC3. Two coating MC2, MC4 was unable to reach an hour duration of fire exposure as 


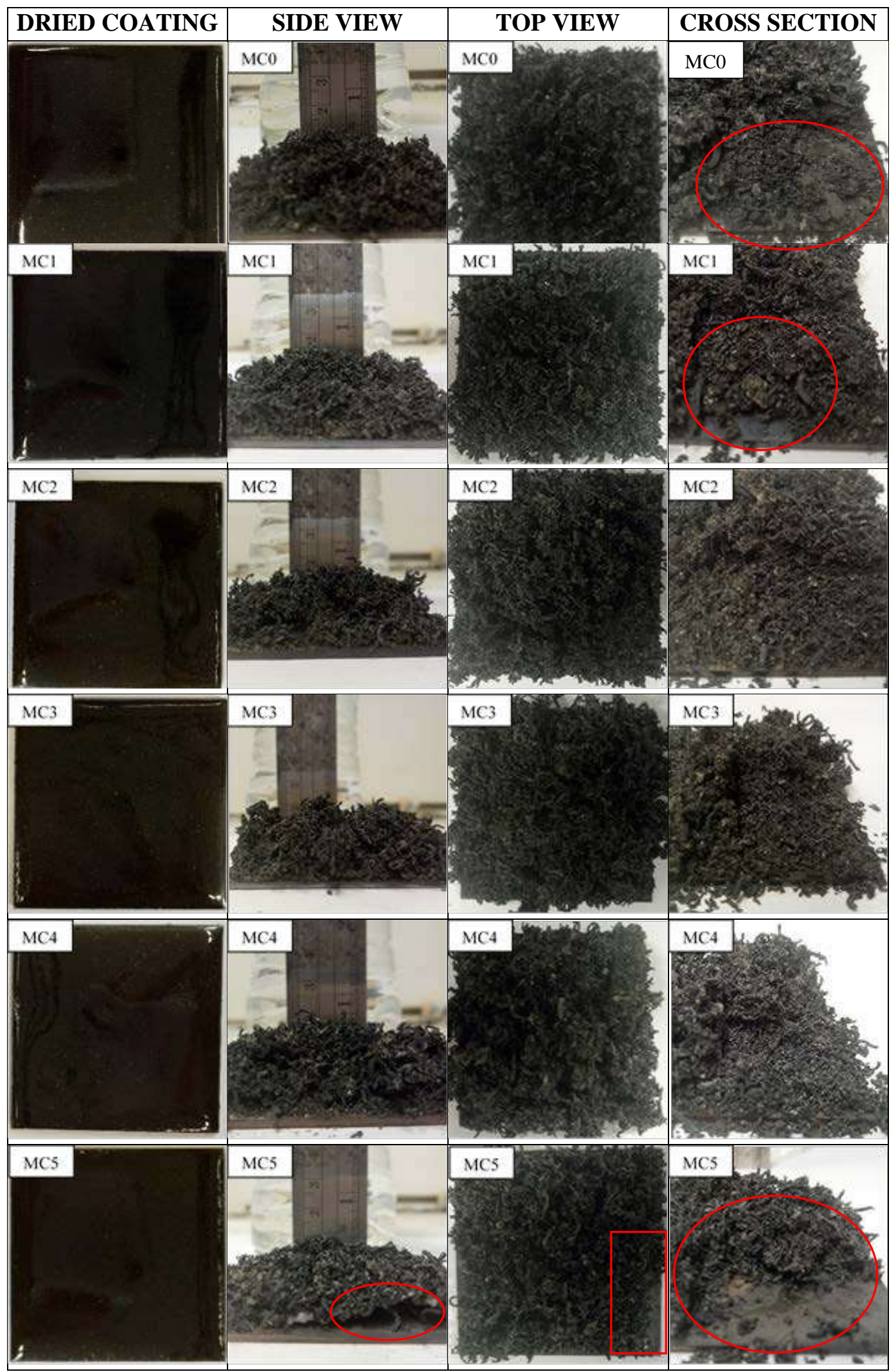

Fig. 2: Control fire test before and after the result

the temperature of the back substrate exceeding $400^{\circ} \mathrm{C}$ due to a crack on the char surface shown in Fig. 4. A clear picture of the substrate was also seen during testing for MC4 samples, as observed in Fig. 5. The result contradicts the IF value obtained from the control fire test, where MC4 has the highest expansion value. This phenomenon suggests that the high expansion of MC4 previously has. 


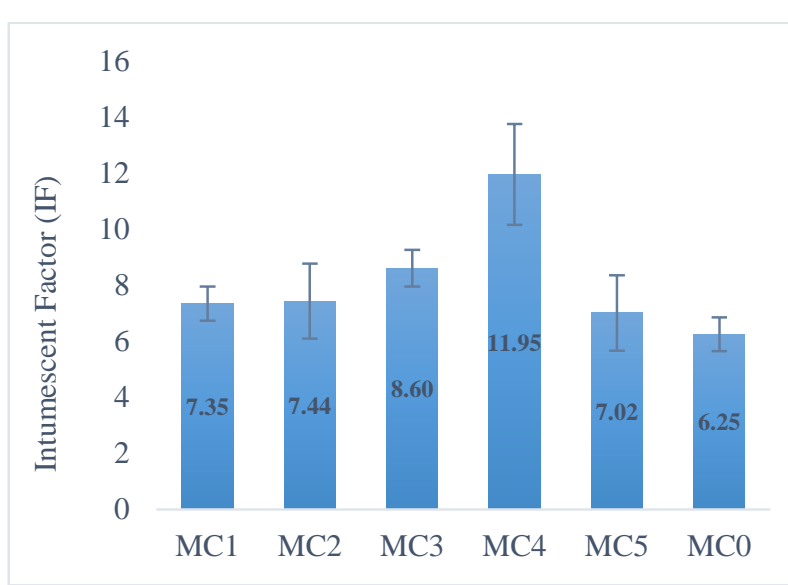

Fig. 3: Bar chart of Intumescent factor for samples with and without mica decreased the char samples' density, thus leading to crack during fire exposure.

Fig 6 demonstrate the time vs temperature graph for all the samples plotted against the ASTM E119 ${ }^{1)}$ fire curved. All the samples, including coating samples without mica having temperature lesser than uncoated steel $\left(927^{\circ} \mathrm{C}\right)$ when exposed to fire for 60 minutes as plotted.

MC2 and MC4 fire test was stopped as the backsubstrate temperature exceeded $400^{\circ} \mathrm{C}$ at minutes 40 . This due to a break on the char, and the protected steel substrate can be observed from the researcher view. MC3 and MC5 were able to withstand the heat without crack with a temperature of $333^{\circ} \mathrm{C}$ and $312^{\circ} \mathrm{C}$ at the end of 60 minutes, respectively. In addition, $\mathrm{MC} 1$ temperature reaching to $426.3^{\circ} \mathrm{C}$ with a crack at the end of the test while the sample without mica while MC0 having a back temperature of $367^{\circ} \mathrm{C}$.

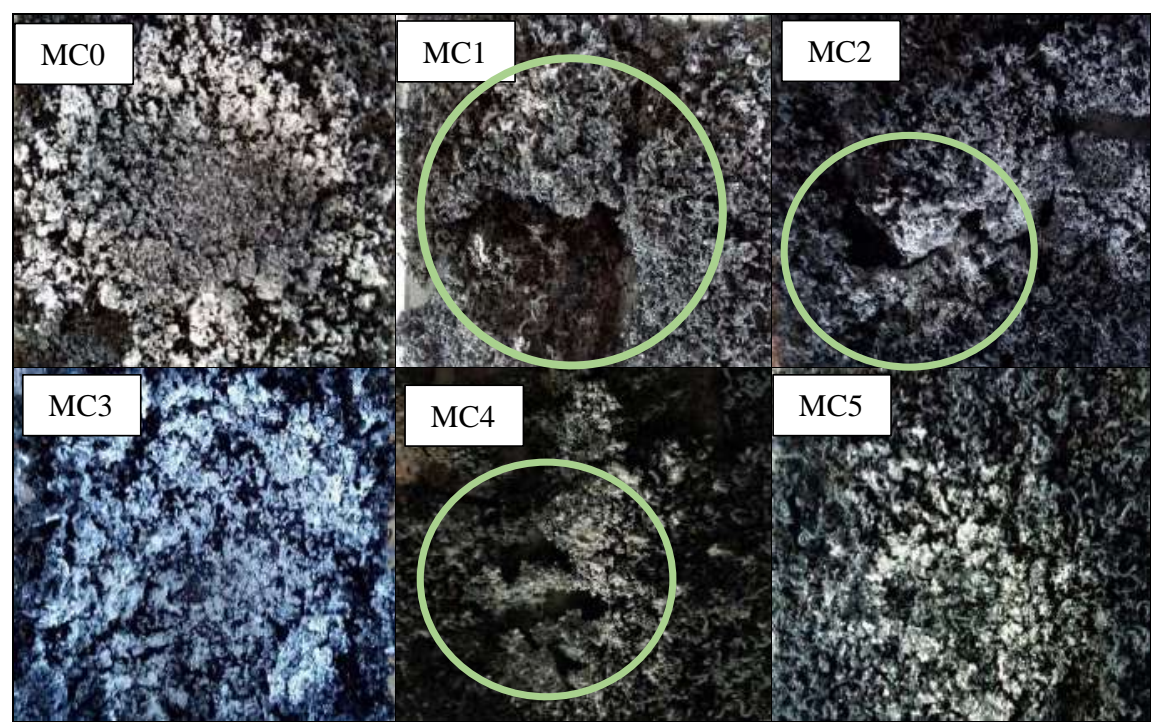

Fig. 4: Direct fire test result samples

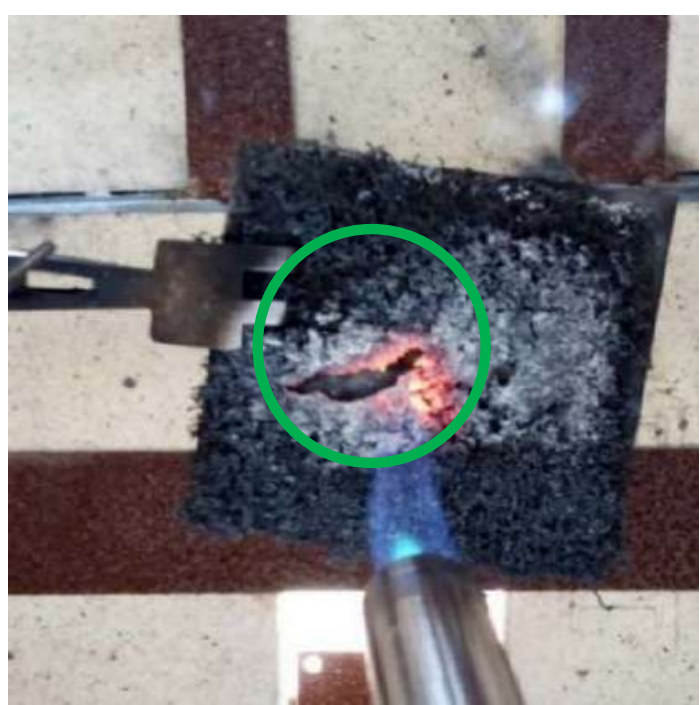

Fig. 5: Holes observed for MC4 samples during the fire test

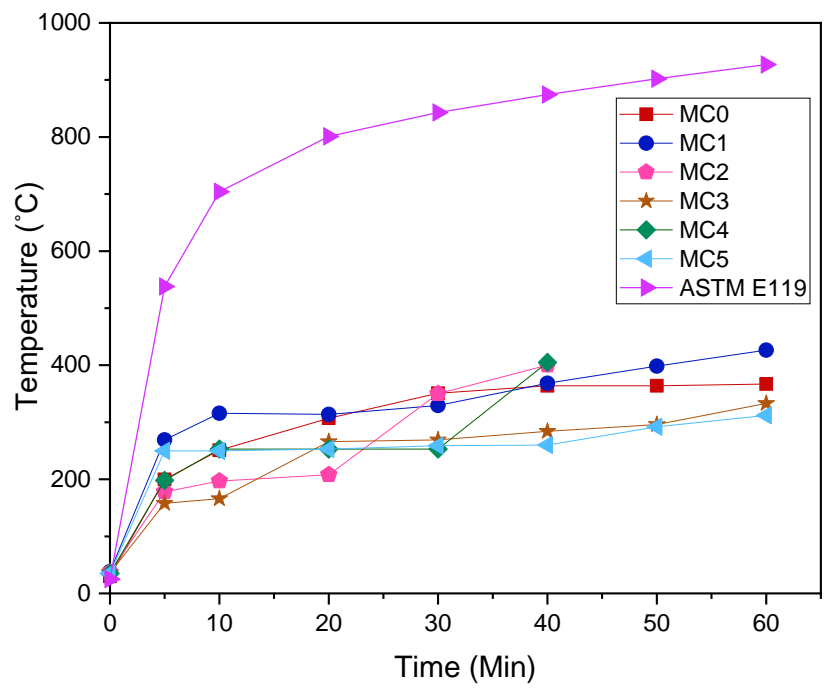

Fig. 6: Time Vs Temperature graph against ASTM E119 fire curve 


\subsection{X-ray Powder Diffraction (XRD)}

$\mathrm{XRD}$ is a rapid analytical technique primarily used to study the composition of residual char of intumescent coating produced at $600^{\circ} \mathrm{C}$. The spectra of sample residual char with and without mica filler are reported in Fig. 7. Boron phosphate was observed in the spectrum $2 \theta=$ $24.23^{\circ}$, coming from boron oxide and APP reaction. A new peak emerges from an intumescent coating sample with mica filler coming from silicon phosphate oxide. These two compounds were known to enhance the antioxidation of the char and thermal stability of the char ${ }^{21)}$. This help to delay the heat penetration rate from the source of fire to the substrate. An increase in carbon compound was also observed when the percentage of mica increases at $2 \theta=$ $26.41^{\circ}$.

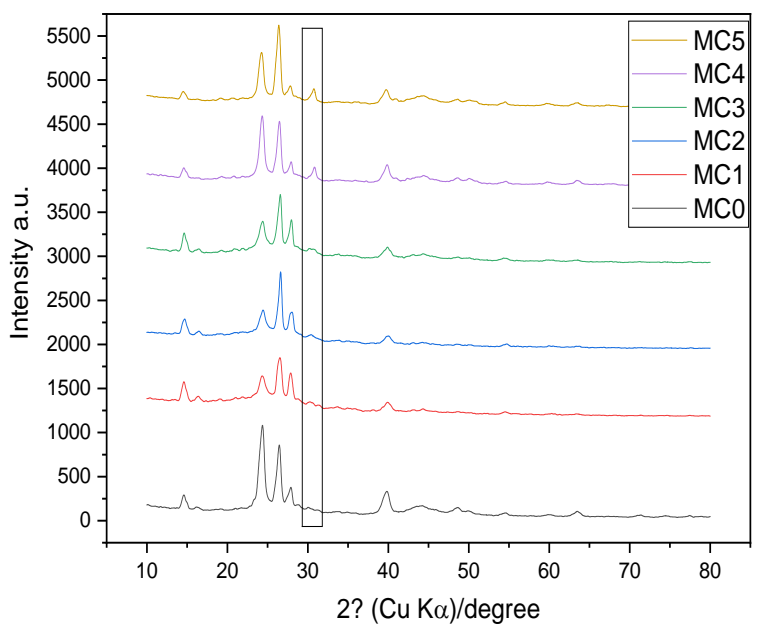

Fig. 7: XRD spectra of samples char residue

\subsection{Thermal analysis}

The char obtained from the previous control fire test was sent for thermogravimetric mainly to determine the thermal decomposition of each material in intumescent fire-retardant coating and the coating itself and predict their thermal stability. Raw mica powder was subjected to the analysis shown in Fig. 8. The degradation of raw mica was broken into two stages due to dehydration and decomposition of mica with residual weight left slightly higher than $70 \%$ when temperature reaching $800^{\circ} \mathrm{C}-900^{\circ} \mathrm{C}$ contributed by mica properties having high thermal stability.

Fig. 9 demonstrate the TG curve of the sample with mica with MC4 observed the highest residual weight of $35.605 \%$, followed by MC3 with 34.96826\%, MC2 33.93255\%, MC1 - 33.71739\% MC1 and MC5 of 26.11818\%. MC3 was chosen to further analyse with MC0 (control formulation) as it has thermally stable result and high expansion and can protect the substrate in an hour duration without a crack. Furthermore, MC3 has a lower weight percentage than MC4 will help to reduce the future cost of developing the intumescent coating in the industry. Fig. 10 and Fig. 11 shows a nearly similar pattern curve between MC3 and MC0. The first degradation step comes from releasing water and $\mathrm{HBO}_{2}$ from boric acid before further degrading boron trioxide ${ }^{20)}$. In the mica sample, the initial degradation temperature (IDT) was slightly lower than MC0 due to dehydration of the mica substance. $T_{m}$ for both samples having slightly similar value with 354.86 for MC0 and 354.95 for MC3. MC3 has a lower value for maximum weight loss weight, Rmax with $7.157 \%$, indicating higher thermal stability for the sample.

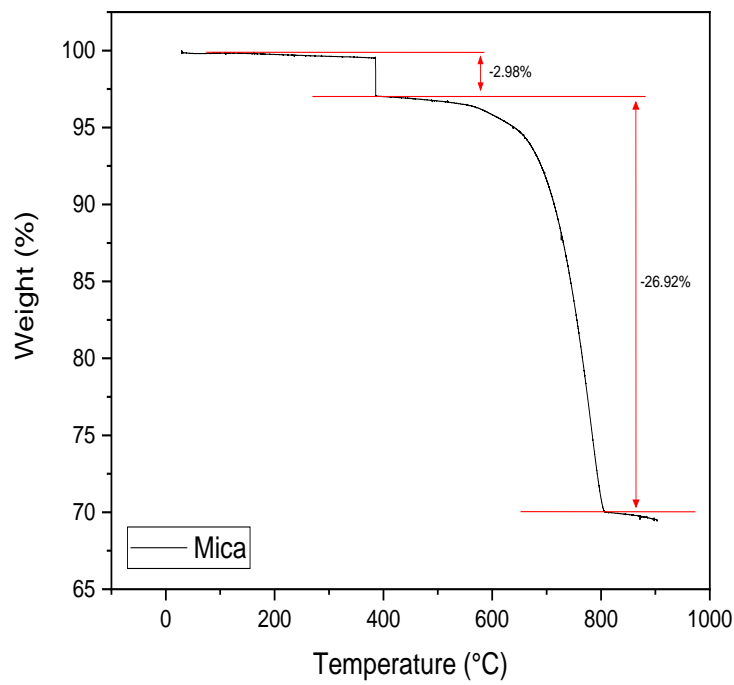

Fig. 8: Raw mica powder thermal analysis

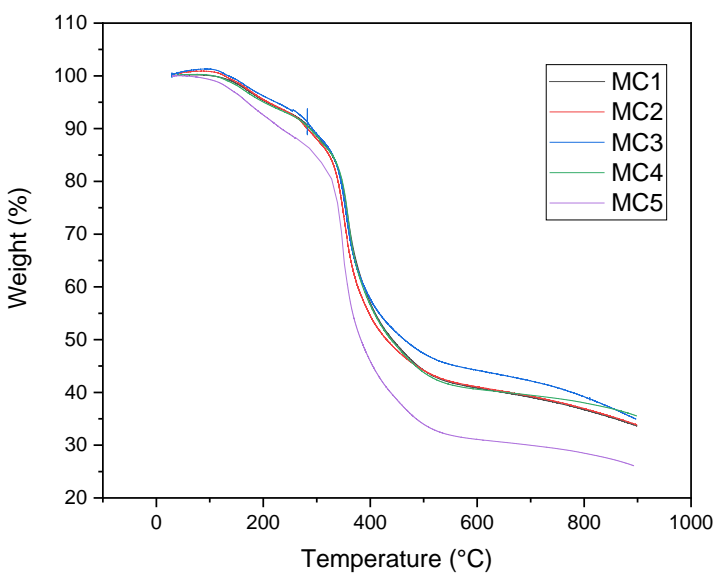

Fig. 9: TG curve of intumescent coating enhanced with mica powder

Table 2: Thermal analysis result for MC0 \& MC3

\begin{tabular}{|c|c|c|c|c|}
\hline Samples & $\begin{array}{c}\mathbf{I D T} \\
\left({ }^{\circ} \mathbf{C}\right)\end{array}$ & $\mathbf{T m}\left({ }^{\circ} \mathbf{C}\right)$ & $\mathbf{R m a x}\left(\% /{ }^{\circ} \mathbf{C}\right)$ & $\begin{array}{c}\text { Char } \\
\text { Yield } \\
(\%)\end{array}$ \\
\hline MC0 & 109.17 & 354.86 & 9.886 & 34.83883 \\
\hline MC3 & 94.8 & 354.95 & 7.157 & 34.96826 \\
\hline
\end{tabular}

Char yield of both samples was observed with a nearly similar percentage with only a slight increase in samples with mica with $34.97 \%$ compared to samples without mica with 34.83\%. Nevertheless, between $850-900^{\circ} \mathrm{C}$, MC3 showing a slope of -0.04605 compare to MC0, with 0.09071. This observation suggests that samples without 
mica will degrade at a high decomposition rate if the analysis was prolonged. The finding was parallel with high thermal stability from raw mica powder observed in Fig. 8.

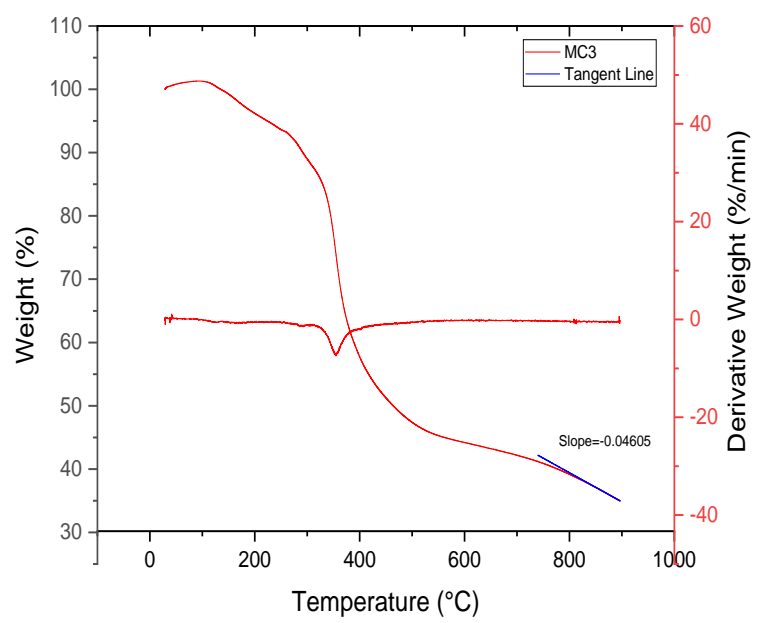

Fig. 10: TG curve of MC3

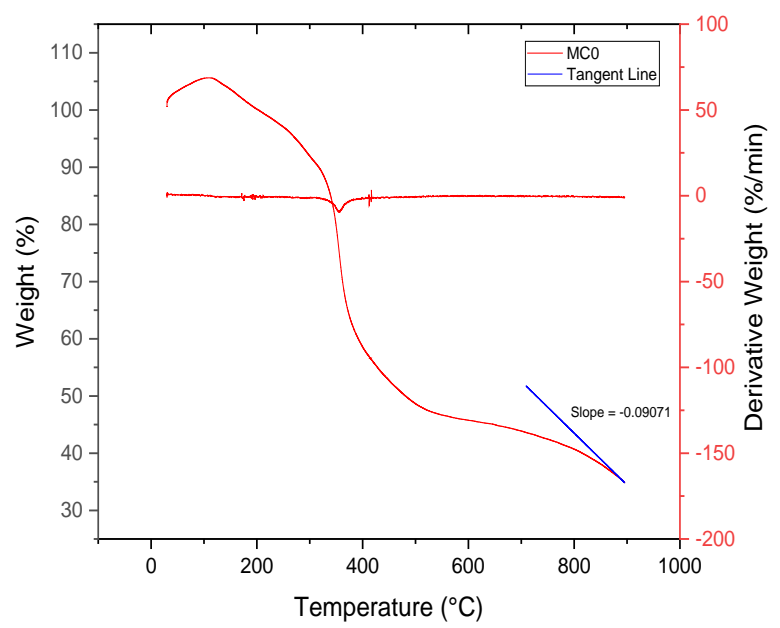

Fig. 11: TG curve of MCO

\subsection{Morphology of Char}

The quality of char produced during combustion reaction determines the insulation property of coatings formulations. A solid, homogenous char residue helps delay heat penetration compared to a fragile char layer ${ }^{22)}$. The structure and microscopy of mineral filler surface are vital as it directly affects surface chemical reaction rates and mechanism ${ }^{23)}$. Sample MC0 exhibit a crack and porous surface layer shown in Fig. 11, proving the cause of the smallest IF value obtained. A ceramization and homogenous surface were observed on MC3 samples with smaller pore improving the trapping of inert gas during the char expansion process. Ceramization is a phenomenon inhibiting the volatiles of polymer thermal decomposition from evacuation by creating ceramic layers in composite surface ${ }^{24), 25)}$ coming from mineral clay. On the surface of the sample with mica char, the integral ceramic layer was created, which does not break into fragment when the material is directly exposed to fire and form a porous ceramic product for volume stability and insulation ${ }^{24)}$. This good morphology suggested that the addition of mica as filler assists in improving the surface structure of intumescent char, thus increasing the thermal performance of the coating.

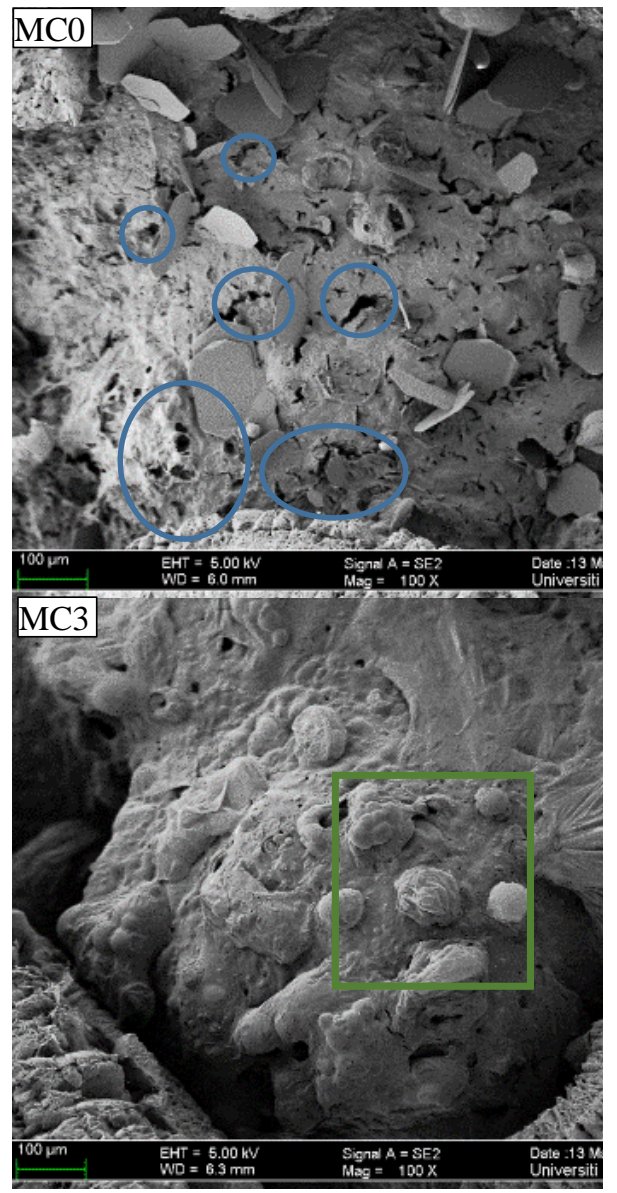

Fig. 12: FESEM image of MC0 and MC3 at 100x magnification

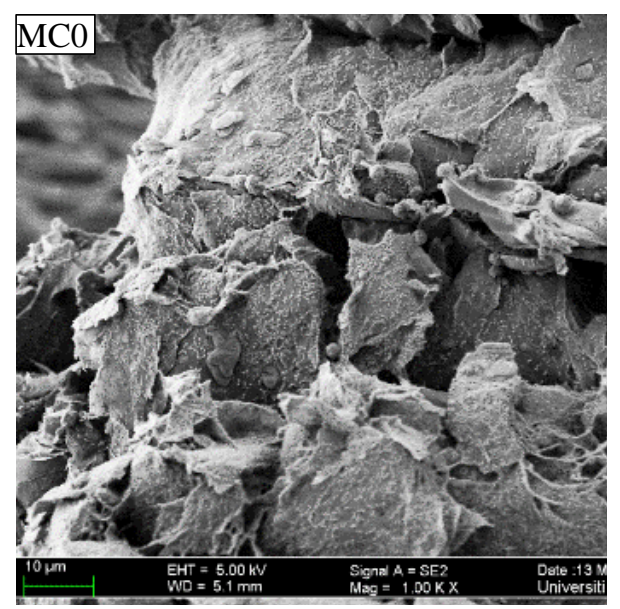




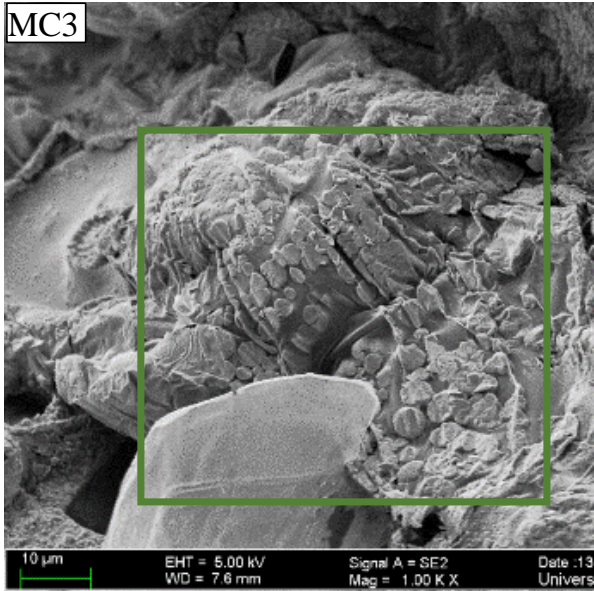

Figure 13: FESEM image of MC0 and MC3 at 1000x magnification

\section{Conclusion}

The effect of mica as filler in intumescent coating formulations was studied in terms of their physical appearance, thermal properties, composition, and morphology. The physical appearance of the intumescent coating surface showed a smooth and glossy surface finish as the percentage of the mica increases due to the pigmentation properties from the mica. An increase of expansion was observed as the percentage of filler increases until at $4 \%$ wt. A high percentage of expansion ratio (MC4) gave poor back steel temperature results due to crack form during the direct fire test. These phenomena might result from less compact char formed during the reaction. MC5 and MC3 showed the lowest recorded back steel temperature from all samples with $312^{\circ} \mathrm{C}$ and $333^{\circ} \mathrm{C}$. This observation also shows that the expansion values should not be the sole indicator of the performance of intumescent char. The thermal analysis on MC3 presented a slight improvement in thermal stability with a second degradation rate of $0.047 \% / \mathrm{min}$ for samples with $3 \%$ mica compared to samples without mica of $0.091 \% / \mathrm{min}$. Morphology analysis for sample MC0 and MC3 showing and an opposite result between the two. MC0 observed with a crack and porous surface layer, while MC3 exhibits a homogenous surface with a smaller pore. The phenomenon might cause the ceramization process that creates a ceramic layer on the surface of the char that does not break into fragment when the material is directly exposed to fire, thus improve the insulation of the coating.

\section{Acknowledgement}

The research was financially supported under the Minister of Higher Education (MOHE), Project titled "Synthesis of Bio Fillers Reinforced Modified Epoxy Based Intumescent Fire Retardant Coating for Structural Protection” Grant No. FRGS/1/2019/TK05/UTP/01/1 under FRGS Scheme. Authors also acknowledge the laboratory support of Advanced and Functional Materials,
Corrosion Research Centre, Universiti Teknologi PETRONAS, Malaysia.

\section{References}

1) American Society for Testing Material, ASTM E11920, Standard Test Methods for Fire Tests of Building Construction and Materials, ASTM International, West Conshohocken, PA, 2016.

2) Mariappan, T., "Recent developments of intumescent fire protection coatings for structural steel: A review" J. Fire Sci., 2016. 34: p. 120-163.

3) Puri, R. G., and A. S. Khanna, "Intumescent coatings: A review on recent progress" J. Coatings Technol. Res., 2017. 14.

4) Jimenez, M., S. Duquesne, and S. Bourbigot, "Intumescent fire protective coating: Toward a better understanding of their mechanism of action," Thermochim. Acta, 2006. 449(1-2): p. 16-26.

5) Weil E D "Fire-protective and flame-retardant coatings - A state-of-the-art review" J. Fire Sci., 2011. 29: p. 259-296.

6) Alongi, J., Z. Han, and Bourbigot S, "Intumescence: Tradition versus novelty. A comprehensive review" Prog. Polym. Sci., 2015. 51: p. 28-73.

7) Yasir, M., F. Ahmad, P. S. M. M. Yusoff, S. Ullah, and M. Jimenez, "Latest trends for structural steel protection by using intumescent fire protective coatings: a review," Surf. Eng., 2019. 36(4): p. 333364.

8) Sato, T., "How is a sustainable society established? A case study of cities in Japan and Germany," EVERGREEN Joint Journal of Novel Carbon Resource Sciences \& Green Asia Strategy, 2016. 3(2): p. 25-35.

9) "Intumescent Coatings Market Analysis By Technology (Water-Based, Solvent-Based, Epoxy Based), By Application (Hydrocarbons, Cellulosic), By End-Use (Construction, Oil \&amp; Gas, Automotive), By Region, And Segment Forecasts, 2018 - 2025," Cision PR Newswire, New York, US, Mar. 02, 2017.

10) Kabir, S., F. Ahmad, K. Malik, N. Nosbi, and L. Gui Llaumat, "Effect of heat resistant coating on the drilled hole quality of hybrid fiber reinforced epoxy composite," EVERGREEN Joint Journal of Novel Carbon Resource Sciences \& Green Asia Strategy, 2020. 7(4): p. 530-537.

11) Selley, R. C., I. R. Plimer, and L. R. M. Cocks, Encyclopedia of Geology, 2004.

12) Dwirekso, I. H., M. Ibadurrohman, and Slamet, "Synthesis of TiO2-SiO2-cuo nanocomposite material and its activities for self-cleaning," EVERGREEN Joint Journal of Novel Carbon Resource Sciences \& Green Asia Strategy, 2020. 7(2): p. 285-291.

13) Alderton, D., "Micas," in Encyclopedia of Geology 
(Second Edition), Second Edition., D. Alderton and S. A. Elias, Eds. Oxford: Academic Press, 2021. p. 326333.

14) Faessler, M. and T. Faessler, "Mica Powder and Pigment Powder - Differences and Use with Epoxy Resin," Acrylgiessen.com, 2020. p. 1-1.

15) Whipkey, S., C. Roman, and K. Seay, "Processing and Characterisation Techniques for a Mica Filled Polymer Composite," J. Undergrad. Mater. Res., 2015. 5(0): p. 54-58.

16) Ribeiro, S. P. da S., L. dos S. Cescon, R. Q. C. R. Ribeiro, A. Landesmann, L. R. de M. Estevão, and R. S. V. Nascimento, "Effect of clay minerals structure on the polymer flame retardancy intumescent process," Appl. Clay Sci., 2018. 161: p. 301-309.

17) Zia-ul-Mustafa, M., F. Ahmad, P. S. M. MegatYusoff, and H. Aziz, "Synergistic effects of mica and wollastonite fillers on thermal performance of intumescent fire retardant coating," AIP Conf. Proc., 2015. 1669(1): p. 1-6.

18) Jimenez, M., S. Duquesne, and S. Bourbigot, "Multiscale experimental approach for developing high-performance intumescent coatings," Ind. Eng. Chem. Res., 2006. 45(13): p. 4500-4508.

19) Mariappan $T$ "Fire Retardant Coatings," in New Technologies in Protective Coatings, 2017. 28(5): doi: 10.5772/67675.

20) Jimenez, M., S. Duquesne, and S. Bourbigot, "Kinetic analysis of the thermal degradation of an epoxy-based intumescent coating," Polym. Degrad. Stab., 2009. 94(3): p. 404-409.

21) Zia-ul-Mustafa, M., F. Ahmad, P. S. M. MegatYusoff, and H. Aziz, "Synergistic effects of mica and wollastonite fillers on thermal performance of intumescent fire retardant coating," AIP Conf. Proc., 2014. 1669: p. 1-6.

22) Amir, N. et al., "Synergistic Effects of Titanium Dioxide and Zinc Borate on Thermal Degradation and Water Resistance of Epoxy Based Intumescent Fire Retardant Coatings," Key Eng. Mater., 2017. 740: p. 41-47.

23) Lapčík, L., M. Vašina, B. Lapčíková, E. Otyepková, and K. E. Waters, "Investigation of advanced mica powder nanocomposite filler materials: Surface energy analysis, powder rheology and sound absorption performance," Compos. Part B Eng., 2015. 77: p. 304-310.

24) Bielinski, D. M., R. Anyszka, Z. Pedzich, and J. Dul, "Ceramizable Silicone Rubber-Based Composites," Int. J Adv Mater Manuf., 2012. p. 1-6.

25) Anyszka, R. and D. Bieliński, "Introduction to Ceramizable Polymer Composites," Vestn. Volgogr. Gos. Univ. Ser. 10. Innov. deiatel'nost', 2014. 6(6): p. 26-35. 